\title{
Inclusion and equity in education: Current policy reform in Nova Scotia, Canada
}

\author{
Jess Whitley ${ }^{1}$ (D) Trista Hollweck ${ }^{1}$ (D)
}

Published online: 9 September 2020

(C) UNESCO IBE 2020

\begin{abstract}
This article aims to explore the context of inclusive education policy in Canada, and to highlight the particular case of inclusive education policy reform in the province of Nova Scotia. As with most other provinces and territories, inclusive education policy in Nova Scotia has broadened to include a lens of equity, with a focus on not only students with special education needs, but all students - particularly those most often marginalized by and within Canadian school systems. The article reflects on the first phase of the developmental evaluation process which took place prior to full implementation of the policy. Four interconnected key themes emerge: 1) the shifting roles and identities for educators and specialized staff; 2) the changing roles of classroom teachers; 3 ) the importance of support to ensure effective universal and differentiated classroom practices; and 4) the professional learning of school staff. Although situated within the Nova Scotian and the national Canadian context, the discussion and implications can readily be applied to international systems engaged in developing and implementing broad inclusive education policy.
\end{abstract}

Keywords Inclusive education · Educational policy $\cdot$ Policy reform $\cdot$ Developmental evaluation $\cdot$ Canada $\cdot$ Nova Scotia

Inclusive education has, for many years, been viewed as a global goal for education systems. It has been 26 years since international participants came together in Salamanca,

Research for this article was supported by a research contract awarded to the first author by the Nova Scotia Department of Education and Early Childhood Development.

Jess Whitley

jwhitley@uottawa.ca

Trista Hollweck

thollwec@uottawa.ca

1 Faculty of Education, University of Ottawa, 145 Jean-Jacques-Lussier Private, Ottawa, ON K1N 6N5, Canada 
Spain to discuss policy shifts required to promote inclusive education. They concluded that:

Regular schools with this inclusive orientation are the most effective means of combating discriminatory attitudes, creating welcoming communities, building an inclusive society and achieving education for all; moreover, they provide an effective education to the majority of children and improve the efficiency and ultimately the cost-effectiveness of the entire education system. (UNESCO 1994, p. 3)

An inclusive education system weaves equity into all elements and processes framed by a belief that diversity, be it based on ability, racial, cultural or linguistic communities, socioeconomic status or gender identity, is valued and that a quality education for all students is a human right (UNESCO 2017). Slee (2019) further describes its role in promoting democracy and belonging for students, particularly those most often excluded from educational and broader communities:"...inclusive education embraced a commitment to dismantling exclusions that formed the foundations for the oppression of vulnerable individuals and population cohorts" (p. 910).

The goal of the current paper is to explore the context of inclusive education in Canada, and to highlight the particular case of inclusive education policy reform in the province of Nova Scotia. Specifically, in this paper we reflect on the process we are currently engaged in, namely a developmental evaluation of a new inclusive education policy in the province of Nova Scotia, and initial findings emerging from this work.

\section{Provincial contexts: Inclusion and equity}

Across Canada, where education is provincially, rather than federally organized, all provinces and territories have demonstrated a commitment to the ideals of inclusion and equity (Hutchinson and Specht 2019). Several provincial and territorial policies related to inclusive education have been re-imagined over the past decade to include a broader perspective on equity as it relates to providing equal access and opportunity to all students, particularly those who have historically been marginalized or viewed as unsuccessful in Canada's education systems (Government of Alberta 2020; Ontario Ministry of Education 2009; The Social Planning Council of Winnipeg 2016). This focus is in contrast to previous and in some provinces, current policies where inclusive education refers primarily to students with special education needs (Province of British Columbia 2020). The importance of valuing and reflecting the diversity of student identity, including ancestry, ethnicity, gender identity, intellectual ability, and socio-economic status in schools, as well as identifying and dismantling systemic barriers is often highlighted. This type of equity and inclusion policy is reflective of international efforts by organizations like the UN with Sustainable Development Goals that include a need to "ensure inclusive and equitable quality education and promote lifelong learning opportunities for all" (United Nations 2015, p. 14).

The persistence of educational inequities (among others) for certain populations has been noted across Canada by those within and beyond the country borders (George et al. 2020; Gordon and White 2014; United Nations 2017). As an example, Black students, those who self-identify as indigenous and those with disabilities are significantly less likely to experience the opportunities and successes of their peers within provincial education systems (Canadian Human Rights Commission 2017; James and Turner 2017; Province of Nova Scotia 2020a). Recognition of continued disparities among student experiences and 
outcomes has propelled recent efforts in provinces including Nova Scotia to collect and share achievement and wellbeing-related data that is disaggregated in a number of ways (Ontario Ministry of Education 2017; UNICEF Canada 2019). This approach will in theory allow for greater attention to the gaps that exist and guide policies and programming to improve outcomes for students marginalized by and within education systems, suggesting both an educational and social justification (Campbell 2020).

\section{Inclusion and equity vs. special education?}

While many necessary efforts related to equity and inclusion emerge within and across provinces and territories, approaches differ with respect to the positioning of these alongside deeply entrenched special education policies. It has been noted by Ainscow (2019) that a focus on including students with disabilities "should be seen as an essential part of an overall strategy for promoting inclusion and equity, not as a separate policy strand" (p. 6). Across jurisdictions, separate special education policies, some of which have been developed or updated within the past 5 years, continue to exist in parallel with the equity efforts (BC Ministry of Education 2016; Ontario Ministry of Education 2017; Province of Manitoba 2017; Province of Nova Scotia 2008).

In terms of class placement, which is how we historically have defined inclusive education, most students with special educational needs in Canada are educated in regular classrooms, with varying levels of "pull out" service provision; segregated classes and a small number of segregated schools also exist in most provinces and territories (Specht et al. 2016). Certain groups of students, in particular those with intellectual and developmental disabilities, are over-represented in segregated settings in Canadian school systems (Reid et al. 2018). Within the range of placements available, students with disabilities may be included socially and/or may be supported in engaging with the regular curriculum with same-age peers. However, as in an analysis of inclusive education in Ontario by Parekh (2018), "it is critical to actively explore into what are we including students. How do we ensure the environment, curriculum, and climate are ones which students can experience a sense of belonging, a sense of membership and shared power?" (para. 4). Physical placement is not synonymous with inclusion.

In implementing inclusive education, provincial and territorial ministries of education all include some mention of universal design for learning (UDL) and differentiated instruction (DI) as pedagogical and assessment practices that can facilitate teaching and learning in diverse, inclusive settings (Whitley et al. 2019). UDL principles can align with practices of different levels or "tiers" of intervention and support - typically three (Katz 2013). In Canada, multi-tiered systems have been in varying stages of adoption for many years, in the form of Response to Intervention (RTI) (McIntosh et al. 2011). RTI in many provinces is intended to shift from a traditional approach where funding and programming are based on a testing, identification, and placement process to a focus on identifying individual student strengths and needs and to providing interventions where needed. While considering the needs of all learners is possible within a tiered system, the language surrounding UDL, MTSS and RTI in Canada tends to reflect a focus on students with special education needs (Robinson and Hutchinson 2014). Thus, while policies have shifted in some provinces to adopt a more multidimensional inclusive lens, there continues to be evidence of parallel equity and inclusion conversations. Our current work in the province of Nova Scotia is an opportunity to examine the ways in which a new policy of inclusive education is 
understood and implemented in light of the broader Canadian and international discussions of equity and inclusion.

\section{Inclusive education policy in Nova Scotia}

Since the spring of 2019, our research team based at the University of Ottawa (led by Professors Jess Whitley and Andy Hargreaves) has been engaged in a developmental evaluation of the implementation of a new Inclusive Education Policy in Nova Scotia. This implementation is in its early phases, with fall 2020 set as the official start date of the policy. Nova Scotia is the largest Maritime province in eastern Canada with a population of approximately 940,000; Halifax is the capital city with almost half of the residents of the province. The province has a large rural population of over 40 per cent (Statistics Canada 2019). According to the Canadian Income Survey of 2018, 10.3 per cent of Nova Scotians live below the poverty line which is the highest share in Canada where the average is 8.7 per cent (Province of Nova Scotia 2020b); 24 per cent of Nova Scotian children live in poverty which is the third highest rate in the country (Frank and Fisher 2020).

Within Nova Scotia, approximately 5.7 per cent of the population self-identify as indigenous, the majority of whom are from the Mi'kmaq nation and are recognized as the founding people of Nova Scotia (Province of Nova Scotia 2014). Approximately 2.5 per cent of Nova Scotians identify as African Nova Scotian, most of whom have lived in the province for three generations or more (Province of Nova Scotia 2019a). There is also a strong Acadian and francophone presence (Province of Nova Scotia 2020c).

With respect to the organization of schools across the province, a major shift occurred in 2018 with the adoption of recommendations arising from a review of the education system (Glaze 2018). Glaze made several controversial recommendations including the elimination of elected school boards and the removal of school administrators from the Nova Scotia Teachers Union (NSTU). Many of the suggested changes were heavily criticized (Laroche 2018; Ritchie 2019) and a few were subsequently rejected in response to imminent job action by the NSTU (Nova Scotia Teachers' Union 2018).

The system was reconfigured to contain seven Regional Centres of Education (RCEs), with executive directors who report directly to the EECD - the Francophone school board (CSAP) structure remained unchanged. Most of the newly formed RCEs contain broad geographic swaths of the province with many including extensive rural areas. The Halifax RCE is the most urban region and also the most populated (in all of Atlantic Canada), with 134 schools and approximately 52,000 students; the Tri-County region is among the most rural and has approximately 6,000 students in 22 schools and encompasses over 7,000 square kilometers.

In terms of broad achievement and equity, students in English-language schools in Nova Scotia scored similarly to the Canadian average on reading in the 2018 Programme for International Student Assessment (PISA) test; students in French-language schools scored below the Canadian average (O'Grady et al. 2019). Provincial assessment results in Nova Scotia are regularly disaggregated by student self-identification as either Mi'kmaq or other indigenous ancestry (4 per cent of enrollment), or of African descent (4 per cent of enrollment). The most recent results demonstrate discrepancies in the scores, with indigenous and African Nova Scotian students scoring lower than non-identified peers in all instances (Province of Nova Scotia 2020a). 
While we view equity in terms of achievement as central to inclusion, we know it to be integrally related to wellbeing. Exclusion, isolation, stigmatization and lack of belonging give rise to problems of emotional, mental and physical health - and most certainly impact achievement. Students across Nova Scotia in Grades 4 through 12 were surveyed on topics related to wellbeing and school experiences for the first time in 2019. Many positives were noted in the findings, including high rates of reports of having a close friend or adult to talk to, and generally high academic expectations of self and teachers. Overall, 78 per cent of students reported feeling like they belong at their school, with 72 per cent of students of African descent and 70 per cent of Mi'kmaq/indigenous students in agreement. Notably, only 65 per cent of those with disabilities and 54 per cent of students identifying as LGBTQ2+ felt like they belonged at school. The same four subgroups of students reported feeling less respected than other students and less safe at school than the provincial average.

Over several decades, a number of reviews, reports, and position papers have documented the strengths and needs of the Nova Scotia education system, including the educational disadvantages related to indigenous and African Nova Scotian students (Aylward et al. 2007; Glaze 2018; Njie et al. 2018; Nova Scotia Teachers' Union 2009; Nunn 2006). In addition, in parallel with other provinces in Canada, the concept of inclusive education has expanded beyond students with identified disabilities, to encompass other needs and populations at risk of exclusion and under-achievement such as immigrant and refugee populations, African Nova Scotians, students growing up in poverty, Mi'kmaq communities, and gender-related minorities (NS Department of Education and Early Childhood Development 2020).

A focus on the unique experiences, needs and barriers typifying communities with strong cultural identities and historical presence is not a recent shift in Nova Scotia. With respect to African Nova Scotian students, the Black Learners Advisory Committee (BLAC) report on education was released over 25 years ago (1994) and describes a series of inequities and systemic barriers within the education system, and society broadly. Following the BLAC report many policies, reports and frameworks have continued efforts and shed a critical lens in order to guide improved outcomes for African Nova Scotian students through curriculum, instruction, assessment, leadership and partnerships with families and communities (Enidlee Consultants Inc. 2009; Province of Nova Scotia 2002; Sparks 2012).

Concerns regarding equity were also noted in the report produced by the Commission on Inclusive Education which took place in 2017-2018 (Njie et al. 2018). This report, entitled "Students First", serves as the foundation of the new Inclusive Education Policy and describes obstacles to progress in inclusive education, including inconsistent operationalization and implementation of various policies and procedures. As the commission noted, this lack of shared agreement regarding the basic underpinnings and practices that comprise inclusive education in Nova Scotia limits the potential of collaborative learning communities that are key to ongoing development of pedagogical practice within a culture of inquiry. The commission and its recommendations were strongly supported by the NSTU although concerns regarding a lack of collaboration and transparency continue to be raised in terms of the speed and nature of implementation efforts (Nova Scotia Teachers' Union 2019).

The current Inclusive Education Policy (Province of Nova Scotia 2019b), furthermore referred to as the policy, emerged from the findings and recommendations within the Students First Report (Njie et al. 2018), as well as the broader history and context of Nova Scotia education. The policy was developed by the EECD in consultation with multiple groups and was released to the public in August 2019. Implementation of the policy is 
slated to take effect in September 2020. The policy includes a broad focus on ensuring equity, opening with the statement: "Inclusive education is a commitment to ensuring a high-quality, culturally and linguistically responsive and equitable education to support the well-being and achievement of every student. All students should feel that they belong in an inclusive school-accepted, safe, and valued - so they can best learn and succeed" (Province of Nova Scotia 2019b, p. 1). The eight guiding principles of the policy are listed in Figure 1.

The policy also includes a number of directives which include classroom teachers taking on responsibility for all students, most often in a common learning environment, with support and collaboration. The development of specific school-based teams to support teachers and students are described, along with the directive that "every school will support student well-being and achievement through a Multi-Tiered System of Supports (MTSS)" (Province of Nova Scotia 2019b, p. 4). Finally, a series of roles and responsibilities for each group of education stakeholders (e.g., students, families, teachers, administrators) is detailed.

Following the release and recommendations of the Students First report (Njie et al. 2018), the Government of Nova Scotia announced initiatives and funding that were situated within the umbrella of inclusive education implementation. In the fall of 2018, 191 new positions were added to the education system. These new hires included a mix of positions that were new to the system, as well as additional hiring of existing positions; examples include Child and Youth Care Practitioners, Autism and Behaviour Specialists, Parent Navigators, African Nova Scotian and Mi'kmaq student support workers. In 2019, a second wave of hires (173 positions) were added.

In late 2018, in order to guide and support the implementation of the policy, and to provide greater accountability as recommended in the Students First report, the government sought proposals for a developmental evaluation. Our research team bid successfully and,

Every student can learn with enough time, practice and equitable and responsive teaching.

Every student, including those with special needs, should receive full-day instruction every day, with flexibility based on the student's individual strengths and challenges.

Every student should be taught within a common learning environment (e.g., a classroom) with students of similar age within the community school, with flexibility that is based on, and responsive to, the student's individual strengths and challenges.

Inclusive education values, draws upon, and includes student voices and choices to assist students in achieving their goals.

Every student deserves to belong (affirmed, validated, and nurtured), be safe, and feel welcomed in all aspects of their daily experience.

Inclusive education is a commitment to honour and respect each student's cultural and linguistic identities and knowledge systems

Inclusive education practices use evidence of students' strengths and challenges to determine a system of supports and monitor the effectiveness of those supports.

All partners are committed and empowered to work collectively to identify and eliminate barriers that interfere with students' well-being and achievement.

Figure 1 Nova Scotia inclusive education policy: Guiding principles 
in the spring of 2019, as the policy was being finalized, our research team embarked upon a developmental evaluation of its implementation. The next section details our approach and initial findings.

\section{Nova Scotia inclusive education policy: Developmental evaluation}

The innovation in inclusive education currently underway in Nova Scotia offers an ideal opportunity to interweave a developmental evaluation. The evaluation is an iterative process, whereby our team works with EECD staff and a broader design team to conceptualize implementation of broad system change for inclusive education. As a collective, we are engaged in collaboratively generating the specific questions to guide the developmental evaluation, establishing priorities, identifying what data is required and how it will be collected, interpreting findings, and tracking development to inform next steps whilst considering changing conditions and new information gathered throughout the process.

In our application of developmental evaluation, we situate ourselves within the eight essential principles outlined by Patton (2016) which include evaluation rigor, utilizationfocused, systems thinking, co-creation and timely feedback. Our first few months engaging with the developmental evaluation have been focused on: a) developing relationships with those knowledgeable about, and likely to be affected by the policy; b) developing a greater understanding of the many moving pieces that comprise the Inclusive Education Policy implementation; c) working closely with a design team to guide the ongoing evaluation planning; d) collecting and analyzing data provided by key informants; and e) providing initial feedback to the EECD based on our findings to date.

Our first step was to develop an evaluation design team in consultation with EECD which comprises a teacher, principal, regional executive director, EECD executive directors of early learning and student success and the EECD Director of Research and Partnerships. As researchers "from away", we also began the process of developing relationships with key individuals and groups to support and inform our shared work. A project manager, based in Nova Scotia, was hired to assist with planning and to maintain a consistent local presence in the EECD. Beginning in the summer of 2019, we also engaged in early data collection, which will inform the analysis in the next section.

We travelled to Nova Scotia four times in the first eight months of the evaluation, twice to Halifax, and twice to other regions. Given the pre-implementation phase within which these visits took place, the focus of our evaluation efforts was on: a) developing a deeper sense of the context in which the policy and its implementation was embedded and b) exploring the perceptions of key stakeholders regarding the policy.

To the first goal, we engaged in information-gathering discussions with 24 individuals within and outside of the EECD. Some of these individuals preferred not to be interviewed and to have their perspective captured on a recording and all provided helpful contextual information that informed our ongoing efforts. Our project manager met with key individuals with the EECD on a weekly basis, to stay abreast of ongoing developments and to take part in the everyday conversations of those engaged in the implementation. We also took part in six advisory group or internal leadership meetings, reflecting participation by teachers from across the province, directors of programs and student services from each region and CSAP, regional executive directors and the EECD leadership team.

In addition to our efforts to learn and engage, formal interviews were conducted with 23 key informants, including regional senior staff, school leadership and resource teachers, representatives of unions and professional associations, as well as post-secondary 
institutions that offer Bachelor of Education (teacher preparation) and graduate education programmes. Interviews focused on the roles and contexts of the participants, their knowledge and perceptions of the policy, and hopes and concerns for the policy implementation. The interviews were audio-recorded and were on average 45 minutes in length. Verbatim transcripts of each interview were developed and analyzed thematically.

Four main themes emerged from our analysis of this preliminary series of interviews. These include: 1) Shifting of roles and identities: Who am I and what do you do? 2) The changing roles of classroom teachers: Islands no longer? 3) Inclusion $=$ MTSS and success hinges on Tier 1, and 4) Professional learning: If we teach a teacher to fish.

\section{Shifting of roles and identities: Who am I and what do you do?}

When discussing the inclusion policy, the majority of participants described the state of flux, either present or anticipated, of the roles and responsibilities of a range of school staff. Much of the discussion within these themes focused on new positions within the education system that were added prior to the release of the policy. In general, participants were positive about the addition of the positions and the ways in which these individuals and their skill sets could and in some cases already were benefitting staff, students, parents and community partners.

However, confusion was regularly expressed by participants, both those in the new positions and working alongside, regarding job descriptions, overlap of tasks with those of existing staff, boundaries of responsibilities and a lack of clarity and communication related to the new hires. Efforts were described where regions were mapping the roles and responsibilities of the new positions alongside others with the Multi-tiered System Structure; these efforts were seen as very beneficial.

Some of the concerns expressed by participants related to perceived threats to expertise and identity. One school guidance counsellor stated:

We need the support, but I'm always going to be like, "But what's our role?" because in some ways I've felt like our role has been chipped away at through all of the new supports that have been put in. I know a more positive way to look at it would be there are supports and we got to join with them, but it's hard when in some of these cases, some of these roles, we don't really understand what the role is.

The lack of clarity and alignment was also raised as a barrier to effective supports for students - not knowing who was responsible for what in which type of situation could lead to student needs not being addressed or overlap of services.

\section{The changing roles of classroom teachers: Islands no longer?}

Shifting roles were also discussed by the majority of the participants in response to the perceived emphasis of the inclusion policy on the increased responsibility of classroom teachers to meet student needs. The new Inclusive Education policy states that "Classroom teachers are responsible for teaching all students. Teaching and interventions are expected to happen most often in a common learning environment, such as the classroom. Classroom teachers cannot do this alone" (Province of Nova Scotia 2019b, p. 3).

Participants described the significant shift in mindset and practice that this would necessitate for some teachers who were at an earlier point along an inclusive continuum and who were used to what was described by one participant as the "70s pull out model" which was 
still in evidence in many schools. One regional consultant stated, “....we've got to support those classroom teachers, if we're saying they're the folks that are responsible with support, we got to do more support for them. Way more support".

As is evident in the policy statement above, the shift towards greater responsibility for classroom teachers is intended to be accompanied by greater collaboration. Although many teachers were already working in partnership with other teachers, specialists, families and community, the sense of ownership for planning and programming for students with special education needs in particular was seen in some instances as sitting with a resource or learning centre teacher.

The shift in the policy noted by many participants who were providing specialist supports at the school or regional level (e.g., resource teacher, psychologists, student services consultant) was described as changes in their roles from supporting students to supporting teachers. The policy described how a range of support teachers (currently resource or learning centre teachers) "would provide direct, collaborative support to classroom teachers and students" (Province of Nova Scotia 2019b, p. 3). This is in contrast to the current role of some support teachers which strictly involves working directly with students in a pull-out model or of some psychologists who engage primarily in individual student assessment and intervention. One specialist wondered, "Can we do more in class consultative types of services with our SLPs so that teachers are building their skillsets and understanding what they can do at the classroom level before they are asking for direct therapy whether small group or individual?"

Having greater collaboration within a regular classroom requires an openness that was seen as challenging for some teachers. One regional consultant believed, "The big issue, I think, for teachers is that they're not really used to having people in their classroom... and they feel like they're being judged all the time. And it's not about judging them. It's about supporting them. And with a multi-tiered system of support and inclusive education, you've got to get used to having many people in your room.

\section{Inclusion $=$ MTSS and success hinges on Tier 1}

Although described sequentially, this third theme is tightly interwoven with some aspects of the first two, specifically the shifting roles and responsibilities for regular classroom teachers. There was a very strong and shared belief evident among participants of the importance of Tier 1 described as the need to bring supports to the classroom and the need to ensure effective universal and differentiated classroom practices. One regional leader described how "there's no question that there's an increased focus on excellence in teaching at Tier One, which I am a very strong proponent of" and a school psychologist shared her belief that "the Tier 1 has a ton of potential to really improve overall student learning if we are looking at increasing some of the more evidence-based interventions".

One guidance counsellor described her desire to work more often alongside classroom teachers rather than spending most of her time supporting individual students but also described the overwhelming mental health needs of students in her school and the existing 1:500 ratio of counsellor to students: "And you want to get into the classrooms and do the proactive piece. You do, because you're hitting 30 kids when you're getting in there and doing cyber stuff, when you're doing positive mental health".

In describing ways in which she could meet the needs of a large group of students however, one resource teacher described that supporting individual teachers at the Tier 1 level, in the general classroom, was just not feasible. The long-term view adopted by system 
leaders and supports was less palatable to those working on a daily basis with large caseloads of students:

Well, I usually group my students according to their needs. So ideally, I get into classes, which I do. But a lot of the time, because of the needs in this building, I find that it turns out being a pull-out model...just for the amount of students that I need to see, like I could have upward of 50 students during first intake and another 50 during second intake. So, the needs are high, and it's much more efficient for me to take them all at the same time.

\section{Professional learning: If we teach a teacher to fish}

A need for professional learning emerged from the discussions of the first three themes, where the increasing focus on regular classroom practices at the Tier 1 level and the shifting roles of educators and staff in a number of different positions generally led to the same recommendations from participants: more professional learning.

Discussions of professional learning typically centred around capacity-building among classroom teachers and the role of skill development in building confidence and a willingness to take ownership for students experiencing difficulties. One regional consultant described how she noticed in her work, “... a lot of people don't feel that they have the skill set to be able to deal with students that have diverse learning needs, that they really don't feel that they've had the training... Because if they've been in the school system a long time, differentiation may be not really a concept that's... or UDL, that really is something that they can pull out of their back pocket".

The framing of the multi-tiered system was also applied to teacher professional learning as it was recognized by participants that different teachers working in different roles within different regions would have varying professional learning needs. As with the example provided by the resource teacher describing the necessity of a pull-out approach, a shift to a capacity-building versus a child-fixing mindset is a long-term view likely to be challenging for many teachers overwhelmed by day-to-day challenges. One regional consultant described this view:

But you really have to look at the staff that you have and the expertise and how can we make this work if we do things in a different fashion. Because it's about building capacities, the other thing, and that's what a lot of the time people aren't seeing. They just want the immediate fix or the immediate, like, "Come and help me right now", not realizing that if we teach them how to fish it's going to be something that they can use for a long time and the skill set that they develop this year is going to... It is about building their own repertoire as far as I'm concerned, in terms of skill set.

A number of challenges were described in considering the professional learning required. A lack of substitute teachers often resulted in in-service opportunities being scheduled after school hours which was not seen as ideal and often precluded the involvement of staff whose workdays were scheduled in different ways (e.g., education assistants).

Opportunities to collaborate with other schools for professional learning was seen as very valuable but again challenges were noted in terms of the amount of travel required in the often geographically large, rural areas typical of many regions in Nova Scotia and the costs of releasing teachers should substitutes become available. Some participants did share examples of committees, advisory groups or informal networks that they were part of that allowed them to discuss and share plans for implementing the inclusive policy. 
Those most senior in the system mentioned the upcoming opportunities to apply for network school projects, an initiative funded by EECD as part of the implementation of the inclusive education policy. These projects were again seen as opportunities to build collective efficacy among school-based educators and administrators to support students more effectively at the Tier 1 level. The majority of the participants had not yet been made aware of this initiative.

In contrast to the wide-ranging scope of the policy, the bulk of the discussion with participants, which was prompted by very open questions, centred around student services and special education needs. This is likely in part to be a reflection of the participant pool, which was heavily weighted with those who traditionally held roles in these areas and who were suggested to us as knowledgeable key informants. It is further reflective of many of those charged with leading the work of implementing inclusive education. A few participants spoke specifically about students who were African Nova Scotian or Mi'kmaq and raised issues of equity and of making connections with families and communities. This broader issue was noted by one regional equity consultant, "In order for this to be effective, it cannot sit with Student Services... And certainly, the optics will be that it is still a policy that is targeting a very specific population. So, there has to be collaboration at the provincial and at the regional level in order for this to be truly realized...If you're going to bring in a team to talk about the implementation of this, it shouldn't be students service coordinators".

\section{Developmental evaluation: Process and next steps}

Feedback of our initial findings, which includes data shared here, as well as recommendations specific to the activities of EECD and the regional contexts was shared with the design team, and then the system at large in the fall of 2019. As is typical of a developmental evaluation, this feedback was intended to be accessible and immediately useful. A subsequent visit in the winter of 2020 began to reveal some of the ways in which these results could and were informing implementation planning. The school closures and shift in priorities resulting from the Covid-19 pandemic have prompted us to re-imagine our activities and the ways in which the policy may be implemented. Ongoing discussions with the EECD have interestingly raised issues of equity that have been revealed by distance and emergency learning efforts - the work of inclusive education remains critical.

\section{Discussion and implications}

This paper has described the current context of inclusive education policy in Canada, with the specific example of our developmental evaluation of the implementation of inclusive education reform in Nova Scotia. Situated within the national Canadian context, the example of Nova Scotia is both typical and unique. As with most other provinces and territories, inclusive education policy in Nova Scotia has broadened to include a lens of equity, and to include a focus on not only students with special education needs, but all students - particularly those most often marginalized by and within Canadian school systems. The inclusion policy currently sits alongside special education policies and procedures - which is also typical of most provinces and territories. Recent inclusion policies reflect both a social and educational justification for inclusive education - a need for a just and equitable society where all students have opportunities to succeed, as well as a belief that in universally 
designing education, we can ensure the needs of some with the benefits for all. According to Ainscow (2020, p. 8),

Progress in relation to inclusion and equity...requires new thinking which focuses attention on the barriers experienced by some children that lead them to become marginalized as a result of contextual factors. The implication is that overcoming such barriers is the most important means of development forms of education that are effective for all children. In this way, inclusion becomes a way of achieving the overall improvement of education systems.

In assessing and informing equity and inclusion efforts, many systems are beginning to collect and examine achievement and wellbeing data. Nova Scotia students performed similar to the Canadian average on most of the elements of the most recent PISA despite unique challenges associated with poverty. Canada's performance is often lauded as reflective of equity alongside excellence. A deeper exploration at a provincial level, however, reveals that academic success and wellbeing are experienced differentially according to self-identification as African Nova Scotian, Mi'kmaq, LGBTQ2+ or with a disability. The success for all approach espoused in many of Canada's equity and inclusion policies, including that of Nova Scotia, needs to also reflect that "all" students do not have the same opportunities and possibilities provided to them within schools and societies.

The disaggregation of data that has become commonplace within Nova Scotia education can facilitate ongoing attention on equity issues. Most provinces are not yet engaging with this type of data analysis and public sharing of results (Campbell 2020). However, while the availability of data can inform discussions and planning, it is the action - the interventions and subsequent shifts in beliefs and local and systemic practices that can lead to change in student opportunities.

A focus on local application is key in exploring, and in our case evaluating, the implementation of policy (Datnow et al. 2001). The mere act of inviting and funding a 3-year developmental evaluation reflects a recognition on the part of the Nova Scotia government that drawing on evidence and a reflexive process throughout the implementation of this type of policy is a high priority. Our presence in the province, including regular discussions with leaders within the EECD and regions, as well as teachers, principals and other school staff, serves as one thread of the implementation. We provoke sharing of understandings, beliefs and practices related to inclusive education which can be personally impactful for participants but can also lead to subsequent shifts in policy implementation as findings are shared with the EECD.

In Nova Scotia, as in many other jurisdictions, regional differences need to be reflected in policy implementation in the same way that student diversity is increasingly being considered in classrooms and schools (Smit 2005). Our initial data reveals consistency and disparities with and across regions with regards to understandings of the policy and its implementation; this is in part related to the role of the participant - whether system leader or classroom teacher - and expected due to the emergent nature of the policy at this point. It also reflects the varied readiness of each region with respect to the policy and the sensemaking engaged in by participants (Snodgrass Rangel et al. 2017; Spillane et al. 2002).

The shift in roles and identities of educators and specialized staff as key to the implementation of this policy, and the need for responsive and collaborative supports encircling the Tier 1 "common learning environment" emerged as powerful themes in our initial findings. Concerns regarding these changes were related to confusion regarding process but also to identity questioning - reflecting the emotional dimension of educational change (Datnow 2018; Hargreaves 2005). The professional learning that so often accompanies 
any discussion of inclusive education reform (Cumming et al. 2018; Turnbull and Turnbull 2020) was also highlighted time and time again by participants - a greater and more varied skill set, and one that is shared with and across educators was seen as essential to policy implementation. Existing research is replete with examples of the power of collaborative structures and communities that support educators in shifting in response to required reforms, particularly when leaders champion and model such work (Ainscow 2016; Butler and Schnellert 2012; Datnow 2018; Hargreaves and O'Connor 2018; Schnellert et al. 2018). The participants we engaged with reflected more senior positions in the system and spoke of individual learning they perceived as required on the part of teachers - the need for collective learning and development was also evident in our analysis (Fullan and Hargreaves 2016). Examining the potential power of teachers as leaders with a voice in change (Hargreaves and Shirley 2019) will be important in our ongoing work in Nova Scotia; facilitated in part by the greater inclusion of the voices of teachers as participants and hopefully those of students and families as well.

Our work in Nova Scotia continues over the next two years and the policy is slated to be implemented province-wide in the fall of 2020. However, schools in Nova Scotia are planning for the school year ahead within similar constraints to those faced by education systems worldwide - school closures and social distancing requirements that may be in place for some time due to the Covid-19 pandemic. The developmental evaluation will need to shift in response and be co-constructed to reflect the realities of the system while still maintaining a persistent focus on inclusive education reform. Luckily the dynamic and nimble qualities and collaborative principles of developmental evaluation are well-suited to this endeavour.

\section{References}

Ainscow, M. (2016). Collaboration as a strategy for promoting equity in education: Possibilities and barriers. Journal of Professional Capital and Community, 1(2), 159-172.

Ainscow, M. (2019). The UNESCO Salamanca Statement 25 years on: Developing inclusive and equitable education systems. Discussion paper prepared for the International Forum on inclusion and equity in education-every learner matters, Cali, Colombia, 11-13 September 2019. https://en.unesco.org/sites/ default/files/2019-forum-inclusion-discussion-paper-en.pdf.

Ainscow, M. (2020). Promoting inclusion and equity in education: Lessons from international experiences. Nordic Journal of Studies in Educational Policy, 6(1), 7-16.

Aylward, L., Farmer, W., \& MacDonald, M. (2007). Minister's review of services for students with special needs: Review committee report and recommendations. https://www.ednet.ns.ca/docs/review-commi ttee-report-e.pdf.

BC Ministry of Education (2016). Special education services: A manual of policies, procedures and guidelines. https://www2.gov.bc.ca/assets/gov/education/administration/kindergarten-to-grade-12/inclusive/ special_ed_policy_manual.pdf.

Black Learners Advisory Committee (1994). BLAC report on education: Redressing inequity-empowering Black learners. https://www.ednet.ns.ca/acs/files-acs/docs/blacreportoneducationvol1-3.pdf.

Butler, D. L., \& Schnellert, L. (2012). Collaborative inquiry in teacher professional development. Teaching and Teacher Education, 28(8), 1206-1220.

Campbell, C. (2020). Educational equity in Canada: The case of Ontario's strategies and actions to advance excellence and equity for students. School Leadership and Management, 1-20.

Canadian Human Rights Commission (2017). Left out: Challenges faced by persons with disabilities in Canada's schools. https://www.chrc-ccdp.gc.ca/eng/content/left-out-challenges-faced-persons-disab ilities-canadas-schools.

Cumming, J., Tones, M., Day, C., \& Heck, E. (2018). Enhancing inclusive education through teacher education reforms. In C. Wyatt-Smith \& L. Adie (Eds.), Innovation and accountability in teacher education (pp. 201-221). Singapore: Springer. 
Datnow, A. (2018). Time for change? The emotions of teacher collaboration and reform. Journal of Professional Capital and Community, 3(3), 157-172.

Datnow, A., Hubbard, L., \& Conchas, G. (2001). How context mediates policy: The implementation of single gender public schooling in California. Teachers College Record, 103(2), 184-206.

Enidlee Consultants (2009). Reality check: A review of key program areas in the BLAC report for their effectiveness in enhancing the educational opportunities and achievement of African Nova Scotian learners. https://www.ednet.ns.ca/docs/realitycheckfinalreportforweb.pdf.

Frank, L., \& Fisher, L. (2020). 2019 report card on child and family poverty in Nova Scotia: Three decades lost. Canadian Centre for Policy Alternatives. https://www.policyalternatives.ca/sites/default/ files/uploads/publications/Nova\%20Scotia\%20Office/2020/01/2019\%20report\%20card\%20on\%20 child $\% 20$ and $\% 20$ family $\% 20$ poverty.pdf.

Fullan, M., \& Hargreaves, A. (2016). Bringing the profession back in: Call to action. Oxford, OH: Learning Forward.

George, R. C., Maier, R., \& Robson, K. (2020). Ignoring race: A comparative analysis of education policy in British Columbia and Ontario. Race Ethnicity and Education, 23(2), 159-179.

Glaze, A. (2018). Raise the bar: A coherent and responsive education administrative system for Nova Scotia. https://www.ednet.ns.ca/adminreview.

Gordon, C. E., \& White, J. P. (2014). Indigenous educational attainment in Canada. The International Indigenous Policy Journal, 5(3), 6.

Government of Alberta (2020). Inclusive education. https://www.alberta.ca/inclusive-education.aspx.

Hargreaves, A. (2005). The emotions of teaching and educational change. In A. Hargreaves (Ed.), Extending educational change (pp. 278-295). Dordrecht: Springer.

Hargreaves, A., \& O'Connor, M. T. (2018). Collaborative professionalism: When teaching together means learning for all. Thousands Oaks, CA: Corwin.

Hargreaves, A., \& Shirley, D. (2019). Leading from the middle: Its nature, origins and importance. Journal of Professional Capital and Community, 5(1), 92-114.

Hutchinson, N. L., \& Specht, J. A. (2019). Inclusion of learners with exceptionalities in Canadian schools: A practical handbook for teachers (6th ed.). Toronto: Pearson Canada.

James, C. E., \& Turner, T. (2017). Towards race equity in education: The schooling of black students in the greater Toronto area. Toronto, Ontario: York University.

Katz, J. (2013). Resource teachers: A changing role in the three-block model of universal design for learning. Winnipeg, Manitoba: Portage and Main Press.

Laroche, J. (2018). Praise and criticism greet sweeping Nova Scotia education report. CBC News: Nova Scotia. https://www.cbc.ca/news/canada/nova-scotia/praise-and-criticism-greet-sweeping-novascotia-education-report-1.4499717.

McIntosh, K., MacKay, L., Andreou, T., Brown, J., Mathews, S., Gietz, C., et al. (2011). Response to intervention in Canada: Definitions, the evidence base, and future directions. Canadian Journal of School Psychology, 26(1), 18-43. https://doi.org/10.1177/0829573511400857.

Njie, A., Shea, S., \& Williams, M. (2018). Students first: Inclusive education that supports teaching, learning, and the success of all Nova Scotia students. https://inclusiveedns.ca/final-report/.

Nova Scotia Teachers' Union (2009). NSTU position paper: Inclusion. https://www.nstu.ca/the-nstu/ communications/nstu-publications/position-papers-and-reports/.

Nova Scotia Teachers' Union (2018). NSTU suspends job action. https://nstu.ca/the-nstu/communicat ions/the-media-room/news-releases?c=nstu-suspends-job-action.

Nova Scotia Teachers' Union (2019). McNeil government needs to fully implement inclusive education reforms. https://nstu.ca/the-nstu/communications/the-media-room/news-releases?c=mcneil-gover nment-needs-to-fully-implement-inclusive-education-reforms.

NS Department of Education and Early Childhood Development (2020). Equity and support for students. https://www.ednet.ns.ca/equity-support-students.

Nunn, D. (2006). Spiralling out of control: Lessons learned from a boy in trouble. Report of the Nunn Commission of Inquiry. https://novascotia.ca/just/nunn_commission/_docs/Report_Nunn_Final .pdf.

O’Grady, K., Deussing, M.-A., Scerbina, T., Tao, Y., Fung, K., Elez, V., et al. (2019). Measuring up: Canadian results of the OECD PISA 2018 study-the performance of Canadian 15-year-olds in reading, mathematics, and science. https://www.cmec.ca/Publications/Lists/Publications/Attac hments/396/PISA2018_PublicReport_EN.pdf.

Ontario Ministry of Education (2009). Ontario's equity and inclusive education strategy. http://www. edu.gov.on.ca/eng/policyfunding/equity.pdf.

Ontario Ministry of Education (2017). Ontario's education equity action plan. http://www.edu.gov. on.ca/eng/about/education_equity_plan_en.pdf. 
Parekh, G. (2018). Exploring inclusion in Ontario. National Inclusive Education Month Commentary \#24. https://inclusiveeducation.ca/2018/03/16/exploring-inclusion-in-ontario/.

Patton, M. (2016). What is essential in developmental evaluation? On integrity, fidelity, adultery, abstinence, impotence, long-term commitment, integrity, and sensitivity in implementing evaluation models. American Journal of Evaluation, 37(2), 250-256. https://doi.org/10.1177/1098214015626295.

Province of British Columbia (2020). Inclusive education resources. https://www2.gov.bc.ca/gov/content/ education-training/k-12/teach/teaching-tools/inclusive-education.

Province of Manitoba (2017). Student services: Planning and programming for students with special learning needs. https://www.edu.gov.mb.ca/k12/specedu/programming/index.html.

Province of Nova Scotia (2002). Racial equity policy. https://studentservices.ednet.ns.ca/sites/default/files/ RacialEquityPolicy_Webversion.pdf.

Province of Nova Scotia (2008). Special education policy: Nova Scotia. Department of Education, Student Services. https://studentservices.ednet.ns.ca/sites/default/files/speceng.pdf.

Province of Nova Scotia (2014). Key facts: Nova Scotia's Aboriginal population. https://novascotia.ca/abor/ docs/demographics/NSMikmaqFactSheet2014.pdf.

Province of Nova Scotia (2019a). Count us in: Nova Scotia's action plan in response to the international decade for people of African descent-2015-2024. https://ansa.novascotia.ca/sites/default/files/dpadaction-plan.pdf.

Province of Nova Scotia (2019b). Inclusive education policy. https://www.ednet.ns.ca/docs/inclusiveeducat ionpolicyen.pdf.

Province of Nova Scotia (2020a). Nova Scotia assessments and examinations results for students with Mi'kmaq or other indigenous ancestry and students of African descent. https://plans.ednet.ns.ca/sites/ default/files/documents/2019\%E2\%80\%9320_Disaggregated_Results_Release_RWM6.pdf.

Province of Nova Scotia (2020b). Indicators of prosperity. https://novascotia.ca/finance/statistics/topic .asp?fto $=24 \mathrm{x}$.

Province of Nova Scotia (2020c). Acadian affairs and francophonie. https://acadien.novascotia.ca/en/ community.

Reid, L., Bennett, S., Specht, J., White, R., Somma, M., Li, X., et al. (2018). If inclusion means everyone, why not me? https://communitylivingontario.ca/wp-content/uploads/2018/05/If_Inclusion_Means _Everyone_Why_Not_Me_FINAL_s.pdf.

Ritchie, S. (2019). Recommendations for education accountability nowhere to be found a year after the Glaze Report. Global News. https://globalnews.ca/news/4879411/accountability-glaze-report-ns-educa tion/.

Robinson, K., \& Hutchinson, N. (2014). Tiered approaches to the education of students with learning disabilities. https://www.ldatschool.ca/tiered-approaches-to-the-education-of-students-with-learning-disab ilities/.

Schnellert, L., Fisher, P., \& Sanford, K. (2018). Developing communities of pedagogical inquiry in British Columbia. In C. Brown \& C. Poortman (Eds.), Networks for learning: Effective collaboration for teacher, school and system improvement. Abington: Routledge Taylor and Francis Group.

Slee, R. (2019). Belonging in an age of exclusion. International Journal of Inclusive Education, 23(9), 909-922.

Smit, B. (2005). Teachers, local knowledge, and policy implementation: A qualitative policy-practice inquiry. Education and Urban Society, 37(3), 292-306.

Snodgrass Rangel, V., Bell, E. R., \& Monroy, C. (2017). A descriptive analysis of instructional coaches' data use in science. School Effectiveness and School Improvement, 28(2), 217-241.

Sparks, D. (2012). 5 year strategic plan: 2012-2017. http://www.theblackeducators.ca/web/wp-content/ uploads/2012/08/BEA-Strategic-Plan.pdf.

Specht, J., McGhie-Richmond, D., Loreman, T., Mirenda, P., Bennett, S., Gallagher, T., et al. (2016). Teaching in inclusive classrooms: Efficacy and beliefs of Canadian preservice teachers. International Journal of Inclusive Education, 20(1), 1-15.

Spillane, J. P., Reiser, B. J., \& Reimer, T. (2002). Policy implementation and cognition: Reframing and refocusing implementation research. Review of Educational Research, 72(3), 387-431.

Statistics Canada (2019). Population and dwelling count highlight tables, 2016 census. https://www12.statc an.gc.ca/census-recensement/2016/dp-pd/hlt-fst/pd-pl/Table.cfm?Lang=Eng\&T=703\&SR=1\&S=87 $\& \mathrm{O}=\mathrm{A} \& \mathrm{RPP}=25$.

The Social Planning Council of Winnipeg (2016). Towards equity in education. http://mass.mb.ca/wp-conte nt/uploads/2016/06/Equity-in-Education.pdf.

Turnbull, A., \& Turnbull, R. (2020). Rights, wrongs, and remedies for inclusive education for students with significant support needs: Professional development, research, and policy reform. Research and Practice for Persons with Severe Disabilities, 45(1), 56-62. 
UNESCO (1994). The Salamanca statement and framework for action on special needs education. World conference on special needs education: access and quality. Salamanca, 7-10 June. https://www.europ ean-agency.org/sites/default/files/salamanca-statement-and-framework.pdf.

UNESCO (2017). A guide for ensuring inclusion and equity in education. Paris: UNESCO.

UNICEF (2019). Canadian index of child and youth well-being: How the index works. Technical background paper. Toronto, Ontario: UNICEF. https://oneyouth.unicef.ca/sites/default/files/2019-08/How_ the_Index_Works_Canadian_Index_of_Child_and_Youth_Well-being.pdf.

United Nations (2015). Transforming our world: The 2030 agenda for sustainable development. Resolution adopted by the general assembly on 25 September 2015. https://www.un.org/ga/search/view_doc. asp? symbol=A/70/L.1\&Lang=E.

United Nations (2017). Report of the working group of experts on people of African descent on its mission to Canada. New York, NY: United Nations. https://documents-dds-ny.un.org/doc/UNDOC/GEN/ G17/239/58/PDF/G1723958.pdf?OpenElement.

Whitley, J., Gooderham, S., Duquette, C., Orders, S., \& Cousins, J. B. (2019). Implementing differentiated instruction: A mixed-methods exploration of teacher beliefs and practices. Teachers and Teaching, $25(8), 1-19$.

Publisher's Note Springer Nature remains neutral with regard to jurisdictional claims in published maps and institutional affiliations.

Jess Whitley is an associate professor of inclusive education at the University of Ottawa. Her research and teaching are driven by a dedication to improving the school experiences of all students and teachers. Her research focuses on mental health literacy, inclusive education policy, teacher preparation for inclusive education and the wellbeing of children and youth with mental health issues. She conducts research in partnership with colleagues at universities across Canada and engages collaboratively with community organizations including Crossroads Children's Mental Health Centre. Jess is part of the Canadian Research Centre on Inclusive Education and an associate of Inclusive Education Canada, as well as the Centre for Research on Educational and Community Services. In her teaching, she aims to best prepare future teachers of inclusive classrooms and further develop the skills and knowledge of graduate-level learners.

Trista Hollweck is a part-time professor and a project director for the international ARC Education Project, Faculty of Education, University of Ottawa. She is a pracademic who straddles the worlds of research, policy and practice. Trista is a former teacher, vice-principal and school district consultant at the Western Quebec School Board. Her doctoral dissertation examines a school board teacher induction, mentoring and coaching program and its systemic change implications. Trista teaches, researches and publishes about restorative justice, professional learning and development, teacher evaluation, systemic change, mentoring and coaching, teacher induction, as well as pandemic pedagogies and professionalism. Trista received her Bachelor of Arts from McGill University, her Post Graduate Certificate of Education (PGCE) from Moray House at the University of Edinburgh, her Master of Education from the Ontario Institute for Studies in Education (OISE) of the University of Toronto, and her doctorate from the University of Ottawa. 